\title{
Tumor suppressor LKB1 inhibits the progression of gallbladder carcinoma and predicts the prognosis of patients with this malignancy
}

\author{
MING-TAI HU ${ }^{1,2^{*}}$, JING-HAN WANG $^{1 *}$, YONG YU $^{1 *}$, CHEN LIU $^{1}$, \\ BIN LI $^{1}$, QING-BAO CHENG ${ }^{1}$ and XIAO-QING JIANG ${ }^{1}$
}

${ }^{1}$ First Department of Biliary Surgery, Third Affiliated Hospital of PLA Second Military Medical University, Shanghai 200438; ${ }^{2}$ Department of General Surgery, Dahua Hospital of Xuhui District, Shanghai 200237, P.R. China

Received October 30, 2017; Accepted February 2, 2018

DOI: 10.3892/ijo.2018.4466

\begin{abstract}
Gallbladder carcinoma (GBC) represents the most common fatal tumors of the biliary tract. The 3-year or 5-year survival rate for patients with this disease are 30 and 5\%, respectively. Liver kinase B1 (LKB1), a primary upstream kinase of adenosine monophosphate-activated protein kinase (AMPK) necessary for maintaining cell metabolism and energy homeostasis, has been found to be an important tumor suppressor gene in recent years, and its inactivation has also found to be closely associated with tumor growth, metastasis and cancer stem cell (CSC) proliferation. Nevertheless, the function of LKB1 in GBC remains unclear. In this study, we found that the expression of LKB1 in GBC tissues was decreased compared with that in non-cancerous tissues. LKB1 overexpression suppressed the proliferation, metastasis and expansion of GBC CSCs. Mechanically, LKB1 suppressed GBC cell progression via the JAK/signal transducer and activator of transcription 3 (STAT3) pathway. The use of the JAK2 inhibitor, AZD-1480, attenuated the suppressive effects of LKB1 overexpression on the growth, metastasis and selfrenewal ability of the GBC cells, which further demonstrated that JAK/STAT3 was involved in the LKB1-induced suppression of GBC cell growth, metastasis and self-renewal ability. More importantly, the decreased expression of LKB1 was a predictor of a poor prognosis of patients with GBC. On the whole, our data indicate that LKB1 inhibits GBC cell growth, metastasis and self-renewal ability by disrupting JAK/STAT3 signaling, and may thus prove to be a novel prognostic biomarker for patients with GBC.
\end{abstract}

Correspondence to: Professor Xiao-Qing Jiang, First Department of Biliary Surgery, Third Affiliated Hospital of PLA Second Military Medical University, 225 Changhai Road, 200438 Shanghai,P.R. China E-mail: jxq1225@126.com

${ }^{*}$ Contributed equally

Key words: gallbladder carcinoma, liver kinase B1, metastasis, cancer stem cell, signal transducer and activator of transcription 3

\section{Introduction}

Gallbladder carcinoma (GBC) is one of the most common malignancies of the biliary tract, ranked as the 5th most common type of gastrointestinal cancer $(1,2)$. GBC is associated with an aggressive behavior and metastasizes to regional lymph nodes during the early stages of the disease (3). The majority of patients with GBC are diagnosed at the late stages of the disease and the recurrence and chemoresistance rates are very high (4). Over the past decade, the 5-year survival of patients with GBC remains at a low rate of approximately 5\% and the mean survival rate ranges from 13.2 to 19 months $(5,6)$, mainly due to the potent growth properties and early metastastic capacity of the disease. Molecular biological studies on GBC have aimed to shed light on the pathogenesis of the disease in an attempt to prolong the survival time of patients with GBC, by elucidating the underling mechanisms and identifying potential therapeutic targets (7). However, further studies are warranted to fully understand the mechanism responsible for the disease and to identify novel therapeutic targets.

Liver kinase B1 (LKB1) plays important roles in cell polarity, trafficking and metabolism (8). It is involved in maintaining cell metabolism and energy homeostasis (9). A recent study by Yamada and Bastie demonstrated that LKB1 exerted a growth-suppressive effect on cells by activating AMPK and AMPK-related kinases (10), thus playing a vital role in maintaining cell polarity, thereby inhibiting inappropriate expansion of tumor cells (11). LKB1 germline mutations have been detected in patients with Peutz-Jeghers syndrome, a disease characterized by the accumulation of non-cancerous gastrointestinal polyps and an increased risk of cancer (12). Additionally, LKB1 somatic mutations occur more frequently in human lung, cervical and breast cancers (13). However, the regulatory role of LKB1 in GBC remains unknown.

The majority of neoplasms are composed of heterogeneous populations, including a distinct subset of cancer stem cells (CSCs) (14). These cells possess the properties of self-renewal, differentiation potential, resistance to chemotherapy and a high tumorigenicity (15). Previous studies have demonstrated that GBC CSCs can be identified by CD44, CD133, EpCAM and other biomarkers (16-18). Numerous stemness-associated 
transcription factors and signaling pathways have been reported to be involved in GBC CSC maintenance and propagation (19). Accumulating evidence indicates that chemoresistance and recurrence in patients with GBC are closely associated with the existence of GBC CSCs (20-22). Therefore, a more effective therapeutic strategy may be developed if the molecular mechanisms underlying CSC regulation are elucidated (23). However, the detailed regulatory mechanisms responsible for GBC CSC generation and expansion remain far from being fully understood.

In the present study, we found that LKB1 expression was abnormally reduced in $>80 \%$ of GBC tissues, and that the downregulation of LKB1 mRNA expression was associated with the poor prognosis of patients with GBC. In addition, we found that LKB1 suppressed GBC the proliferation, metastasis and expansion of GBC CSCs through the JAK/signal transducer and activator of transcription 3 (STAT3) cascade.

\section{Materials and methods}

Patients and samples. A total of 157 tissue samples were randomly retrieved from patients with GBC who underwent curative resection at the Third Affiliated Hospital of PLA Second Military Medical University [also known as Eastern Hepatobiliary Surgery Hospital (Shanghai, China)]. In total, 40 tissue samples from patients with GBC were used for RT-PCR assay and the clinicopathological characteristics of the patients with GBC are shown in Table I. In addition, 12 tissues from patients with GBC were used for western blot analysis; and 2 tissue samples were used for immunohistochemical analysis. A total of 105 tissue samples were also used for clinical prognosis analysis and the clinicopathological characteristics of these patients are shown in Table II. Overall survival (OS) was defined as the time interval from the date of surgery to the date of death. Cumulative recurrence was defined as the time interval from surgery to the evidence of recurrence. Patient informed consent was also obtained and the procedure of human sample collection was approved by the Ethics Committee of Eastern Hepatobiliary Surgery Hospital.

Cell lines and cell culture. The GBC cell lines, SGC-996 and GBC-SD, were purchased from the Chinese Academy of Sciences, Shanghai, China. The GBC cells were cultured in Dulbecco's modified Eagle's medium (DMEM) supplemented with $10 \%$ fetal bovine serum (FBS) and $2 \mathrm{mM}$ L-glutamine, and $25 \mu \mathrm{g} / \mathrm{ml}$ of gentamicin and maintained at $37^{\circ} \mathrm{C}$ in a $5 \% \mathrm{CO}_{2}$ incubator. All these reagents were purchased from Shanghai Basalmedia Technologies Co., Ltd. (Shanghai, China). The cultured cells were digested with $0.5 \%$ trypsin and moved to a new 6-well plate twice a week.

The lentiviral vector expressing LKB1 and its control virus were produced as previously described (24). The lentiviral vectors were purchased from Shanghai GenePharma (Shanghai, China). The lentiviral vectors were mixed with PolyJet (Polyplus, New York, NY, USA), and then added to the cells. The GBC-SD or SGC-996 cells were infected with LKB1 or its control virus and the stable infectants were screened by puromycin.

The SGC-996 or GBC-SD LKB1 and their control cells were treated with $10 \mu \mathrm{M}$ AZD-1480 (Cat. no. S2162; Selleck. cn) or left untreated, and were then subjected to CCK8 assay
(96 h), Transwell assay (24 h) or spheroid formation assay (7 days).

Cell proliferation assays. For cell proliferation analysis, the GBC-SD or SGC-996 LKB1 and their control cells were seeded in 96 -well plates $\left(3 \times 10^{3}\right.$ cells/well). ATP activity was measured using a Cell Counting kit- 8 at the indicated time-points. The procedure was as follows: The cell suspension $(100 \mu \mathrm{l} /$ well) was inoculated in a 96-well plate, and the plate was pre-incubated in a humidified incubator at $37^{\circ} \mathrm{C}$ for $1 \mathrm{~h}$. This was followed by the addition of $10 \mu \mathrm{l}$ of the CCK-8 solution to each well of the plate, and incubation of the plate for $1 \mathrm{~h}$ in the incubator. Finally, the absorbance was measured at $450 \mathrm{~nm}$ using a microplate reader (Synergy H1; BioTek Instruments, Inc., Winooski, VT, USA).

For cell EdU immunofluorescence staining, the GBC cells were seeded into 96-well plates and examined using the EdU kit (RiboBio, Guangzhou, China). The results were quantified with a Zeiss axiophot photomicroscope (Carl Zeiss, Jena, Germany) and Image-Pro plus 6.0 software.

Colony formation assay. For colony formation assay, the GBC-SD or SGC-996 LKB1 and their control cells were seeded in 12 -well plates $\left(3 \times 10^{3}\right.$ cells/well). The cells were incubated at $37^{\circ} \mathrm{C}$ for 7 days and then fixed with with $10 \%$ neutral formalin for $>4 \mathrm{~h}$. The cells were dyed with crystal violet (Beyotime, Haimen, China). The cells were photographed under a microscope (Olympus, Tokyo, Japan).

Cell migration assay. For cell migration experiments, $2 \times 10^{5}$ cells were seeded into the upper chamber of a polycarbonate Transwell in serum-free DMEM. The lower chamber was supplemented with DMEM containing $20 \%$ FBS as chemoattractant. The cells were incubating for $24 \mathrm{~h}$ and the chamber was fixed with $10 \%$ neutral formalin for $>4 \mathrm{~h}$. The cells were dyed with crystal violet (Beyotime). The cells were then counted under a microscope (Olympus) and the cell number is expressed as the average number of the cells in each field.

Cell invasion assay. For cell invasion experiments, $2 \times 10^{5}$ cells were seeded into the upper chamber of a Matrigel-coated Boyden chamber in serum-free DMEM. The lower chamber was supplemented with DMEM containing 20\% FBS as a chemoattractant. The cells were incubating for $48 \mathrm{~h}$ and the chamber was fixed with $10 \%$ neutral formalin for $>4 \mathrm{~h}$. The cells were dyed with crystal violet (Beyotime). The cells were counted under a microscope (Olympus) and the cell number is expressed as the average number of the cells in each field.

Flow cytometric analysis. The GBC cells were incubated with the primary anti-CD44 (Cat. no. 15675-1-AP; Proteintech, Rosemont, IL, USA) or anti-CD133 (Cat. no. 18470-1-AP; Proteintech) for $30 \mathrm{~min}$ at room temperature. The cells were then subjected to flow cytometry using a MoFlo XDP cell sorter from Beckman Coulter (Indianapolis, IN, USA) according to the manufacturer's instructions.

The GBC-SD LKB1 or SGC-996 LKB1 and their control cells were incubated with the primary anti-CD44 (Cat.no. 15675-1-AP; Proteintech) or anti-CD133 (Cat. no. 18470-1-AP; Proteintech) for $30 \mathrm{~min}$ at room temperature. Flow cytometric analysis 
Table I. Clinicopathological data of patients in cohort 1.

\begin{tabular}{|c|c|}
\hline Variables & No. \\
\hline \multicolumn{2}{|l|}{ Sex } \\
\hline Male & 15 \\
\hline Female & 25 \\
\hline \multicolumn{2}{|l|}{ Age (years) } \\
\hline Medium & 52 \\
\hline Range & $29-75$ \\
\hline \multicolumn{2}{|c|}{ Tumor size (cm) } \\
\hline$\leq 3$ & 12 \\
\hline$>3$ & 28 \\
\hline \multicolumn{2}{|c|}{ Local invasion } \\
\hline Yes & 14 \\
\hline No & 26 \\
\hline \multicolumn{2}{|c|}{ Lymph-node metastasis } \\
\hline Yes & 13 \\
\hline No & 27 \\
\hline \multicolumn{2}{|c|}{ Distant metastasis } \\
\hline Yes & 13 \\
\hline No & 27 \\
\hline \multicolumn{2}{|l|}{ TNM stage } \\
\hline I-II & 19 \\
\hline III-IV & 21 \\
\hline
\end{tabular}

was performed using a MoFlo XDP cell sorter from Beckman Coulter according to the manufacturer's instructions.

Spheroid formation assay. The GBC cells were cultured in a 6-well or 96-well ultra-low attachment culture plate for 1 week, and the total number of spheres was counted under a microscope (Olympus).

Limiting dilution assay. Various numbers (64, 32, 16, 8, 4, 2 cells per well) of GBC-SD or SGC-996 LKB1 and their control cells were seeded into 96-well ultra-low attachment culture plates for 1 week, and the number of spheres was counted under a microscope (Olympus). CSC proportions were analyzed using Poisson distribution statistics and the L-Calc Version 1.1 software program (StemCell Technologies, Inc., Vancouver, Canada) as previously described (25).

Reverse transcription-quantitative PCR. RNA was extracted from the cells and tissues using TRIzol reagent (15596-018; Invitrogen, Carlsbad, CA, USA). Total cDNA was synthesized using the ThermoScrip ${ }^{\mathrm{TM}}$ RT-PCR system (11146-057; Invitrogen). The total mRNA expression in the cells was measured by RT-PCR using the ABI PRISM 7300 Real-Time PCR system (Applied Biosystems, Foster City, CA, USA). The primers were purchased from Invitrogen/Thermo Fisher Scientific (Shanghai, China) and the primers sequences are presented in Table III. The PCR cycling conditions were as follows: $95^{\circ} \mathrm{C}$ degeneration for $10 \mathrm{~min} ; 95^{\circ} \mathrm{C}$ modification for $30 \mathrm{sec}, 60^{\circ} \mathrm{C}$ annealing for $30 \mathrm{sec}, 72^{\circ} \mathrm{C}$ extension for $40 \mathrm{sec}$, total of 40 cycles, $72^{\circ} \mathrm{C}$ terminal extension for $10 \mathrm{~min}$.
Table II. Clinicopathological data of patients in cohort 2.

Variables No

Sex

Male

40

Female

65

Age (year)

Medium

Range

Tumor size $(\mathrm{cm})$

$\leq 3$

$>3$

Local invasion

Yes

No

Lymph-node metastasis

Yes

36

No

Distant metastasis

Yes

No

TNM stage

I-II

III-IV

Table III. Sequences of PCR primers used in this study.

\begin{tabular}{lll}
\hline LKB1 & F (5'- 3') & TTGGGACCCCAGAGAAAACC \\
(human) & R (5'- 3') & CGATGGCGTTTCTCGTGTTT \\
ABCG2 & F (5'- 3') & CGCACAGAGCAAAGCCATTT \\
(human) & R (5'- 3') & GCAAGGGGCTAGAAGAAGGG \\
MDR-1) & F (5'- 3') & CCTAGGAGTACTCACTTCAGGA \\
(human) & R (5'- 3') & CCAATCAGCCTCACCACAGA \\
CD34 & F (5'- 3') & AGGAGAAAGGCTGGGCGAAG \\
(human) & R (5'- 3') & GTTGTCTTGCTGAATGGCCG \\
OCT4) & F (5'- 3') & CTTGCTGCAGAAGTGGGTGGAGGAA \\
(human) & R (5'- 3') & CTGCAGTGTGGGTTTCGGGCA \\
B-actin) & F (5'- 3') & GGCCCAGAATGCAGTTCGCCTT \\
(human) & R (5'- 3') & AATGGCACCCTGCTCACGCA
\end{tabular}

F, forward; R, reverse.

Western blot analysis. The tissue samples from the patients were lysed with cell lysis buffer (Beyotime) followed by supersonic splitting. The total protein was quantified using the BCA Protein Quantification kit. A total of $20 \mu \mathrm{g}$ of protein were subjected to sodium dodecyl sulfate polyacrylamide gel electrophoresis and then transferred onto nitrocellulose membranes. The membranes were blocked with $10 \%$ non-fat milk and incubated with the primary antibodies (LKB1, p-STAT3, STAT3, p-AKT, p-MEK, E-cadherin and GAPDH) 
Table IV. Primary antibodies used in this study.

\begin{tabular}{lllll}
\hline Human antigens & \multicolumn{1}{c}{ Antibody } & Catalogue no. & \multicolumn{1}{c}{ Manufacturer } & Dilution \\
\hline LKB1 & Mouse polyclonal & ab15095 & Abcam, Cambridge, MA, USA & 1:500 for western blot analysis \\
LKB1 & Rabbit polyclonal & $10746-1-$ AP & Proteintech, Wuhan, China & $1: 50$ for IHC \\
p-STAT3 & Rabbit polyclonal & ab76315 & Abcam, Cambridge, MA, USA & $1: 500$ for western blot analysis \\
STAT3 & Rabbit polyclonal & ab119352 & Abcam, Cambridge, MA, USA & $1: 500$ for western blot analysis \\
p-AKT & Rabbit polyclonal & ab38449 & Abcam, Cambridge, MA, USA & $1: 500$ for western blot analysis \\
p-MEK & Rabbit polyclonal & ab96379 & Abcam, Cambridge, MA, USA & $1: 500$ for western blot analysis \\
E-cadherin & Mouse polyclonal & ab1416 & Abcam, Cambridge, MA, USA & $1: 500$ for western blot analysis \\
GAPDH & Mouse monoclonal & ab8245 & Abcam, Cambridge, MA, USA & $1: 1000$ for western blot analysis \\
CD44 & Rabbit monoclonal & $15675-1-$ AP & Proteintech, Wuhan, China & $1: 10$ for FACS \\
CD133 & Rabbit monoclonal & $18470-1-$ AP & Proteintech, Wuhan, China & $1: 10$ for FACS
\end{tabular}

A

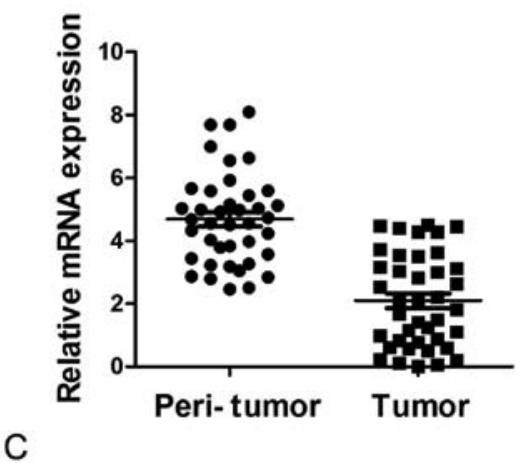

B

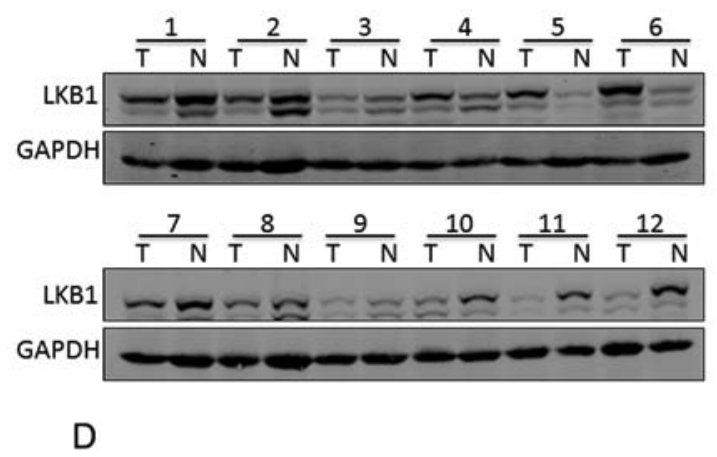

D

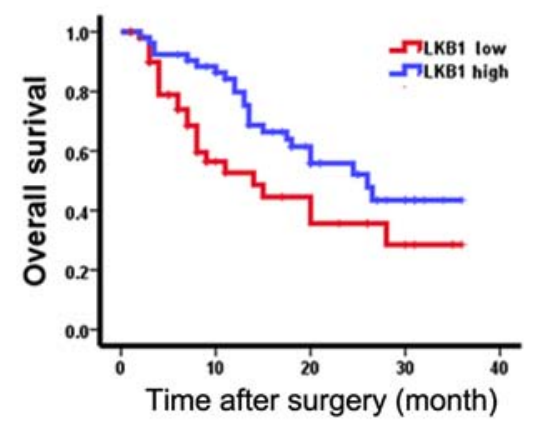

$\mathrm{E}$

Case 2

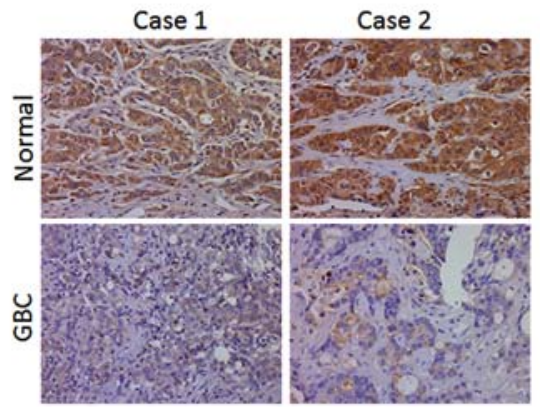

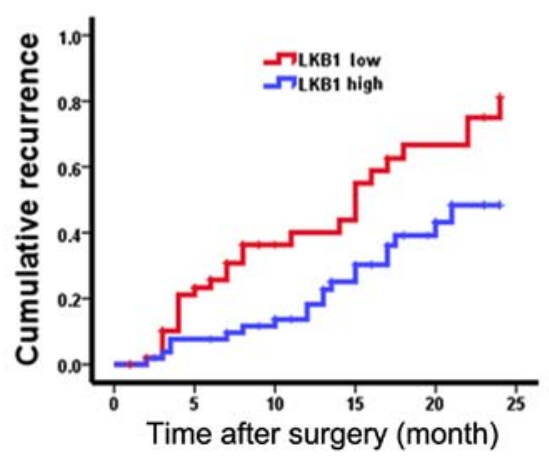

Figure 1. Expression of LKB1 is decreased in human gallbladder carcinoma (GBC) tissues. (A) mRNA expression of LKB1 in 40 pairs of GBC tissues (T) and neighboring non-cancerous tissues (N) was examined by RT-qPCR. (B) Protein expression of LKB1 in 12 pairs of GBC tissue (T) and neighboring non-cancerous tissues $(\mathrm{N})$ was determined western blot analysis. (C) Immunohistochemical staining of LKB1 in human GBC tissues and neighboring noncancerous tissues. (D and E) The expression of LKB1 was scored in 105 human GBC samples. Overall survival (OS) ( $\mathrm{P}=0.021)$ and cumulative recurrence rate $(\mathrm{P}=0.014)$ after surgery were compared between the 'low-LKB1' expression group $(\mathrm{n}=53)$ and the 'high-LKB1' expression group $(\mathrm{n}=52)$. 
A
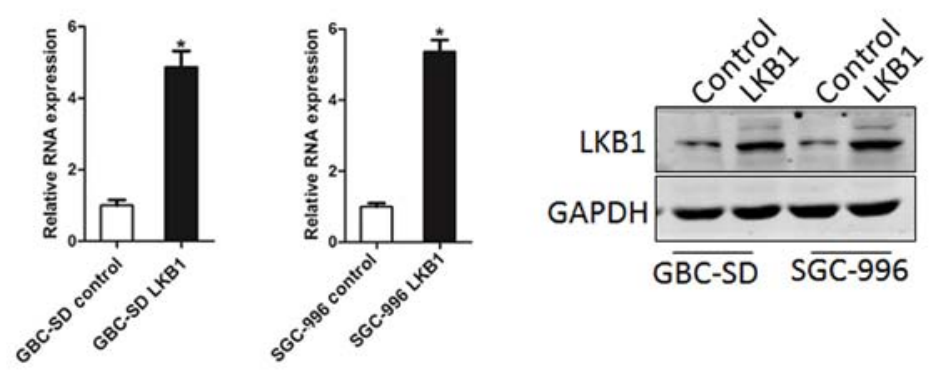

B
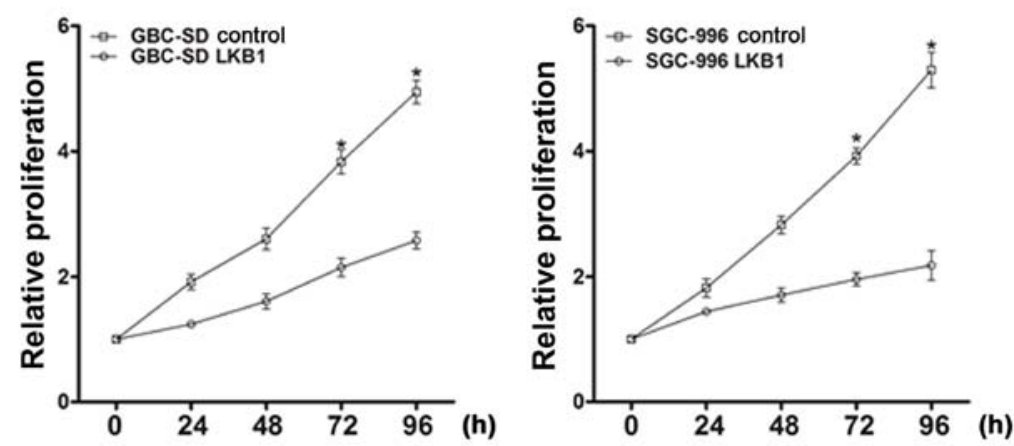

C

D

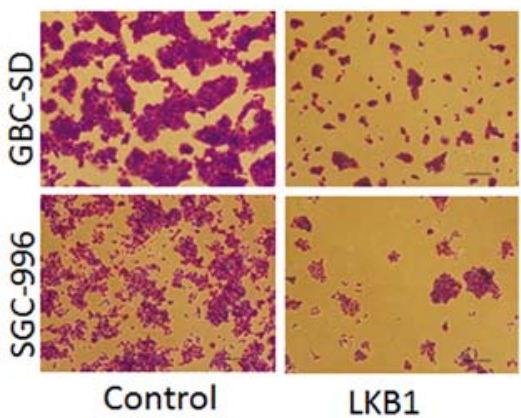

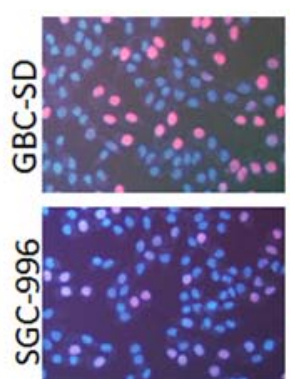

Control

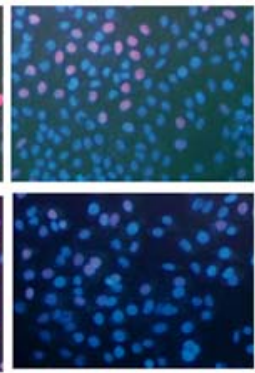

LKB1

Figure 2. LKB1 overexpression inhibits gallbladder carcinoma (GBC) cell proliferation. (A) GBC-SD and SGC-996 cells were infected with an LKB1 overexpression lentivirus and the sable infectants were examined by RT-qPCR and western blot analysis. (B) The proliferation of GBC-SD LKB1 or SGC-996 LKB1 cells and the control cells was examined by CCK8 assay. (C) The colony formation ability of GBC-SD LKB1 or SGC-996 LKB1 and their control cells were performed by colony formation assay. (D) The proliferation of GBC-SD LKB1 or SGC-996 LKB1 and the control cells was also examined by EdU immunofluorescence staining assay.

overnight. The protein band, specifically bound to the primary antibody, was detected using an IRDye $800 \mathrm{CW}$-conjugated secondary antibody and LI-COR imaging system (LI-COR Biosciences, Lincoln, NE, USA).

The cells were also lysed using cell lysis buffer, and western blot analysis was then carried as described above. The total protein was quantified using the BCA Protein Quantification kit. A total of $20 \mu \mathrm{g}$ protein of cell extracts were subjected to western blot analysis with one of the antibodies against LKB1, STAT3, p-AKT, p-MEK, E-cadherin and GAPDH (Abcam, Cambridge, MA, USA). The protein band, specifically bound to the primary antibody, was detected using an IRDye $800 \mathrm{CW}$-conjugated secondary antibody and LI-COR imaging system (LI-COR Biosciences). The details of the antibodies used in this study are shown in Table IV.

Luciferase reporter assay. The GBC cells transfected with the pGL-STAT3-luc and pRL-TK-Renilla-luc plasmids (GenePharma). Luciferase activity was measured using a Synergy 2 Multidetection Microplate Reader (BioTek Instruments, Inc.). Data were normalized for transfection efficiency by dividing the firefly luciferase activity by Renilla luciferase activity.

Statistical analysis. GraphPad Prism (GraphPad Software, Inc. La Jolla, CA, USA) was used for all statistical analyses. Statistical analysis was carried out using a t-test or the Bonferroni Multiple Comparisons test. A value of $\mathrm{P}<0.05$ was considered to indicate a statistically significant difference.

\section{Results}

LKB1 expression is downregulated in human GBC tissues and predicts the poor prognosis of patients with $G B C$. To explore the function of LKB1 in GBC progression, we examined the mRNA and protein expression of LKB1 in GBC tissues. As shown in Fig. 1A, LKB1 mRNA expression was markedly decreased in the tumor tissue, namely in $82.5 \%$ of the GBC cases $(33 / 40)$ 
A

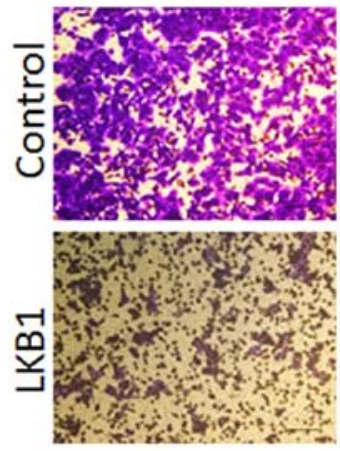

C

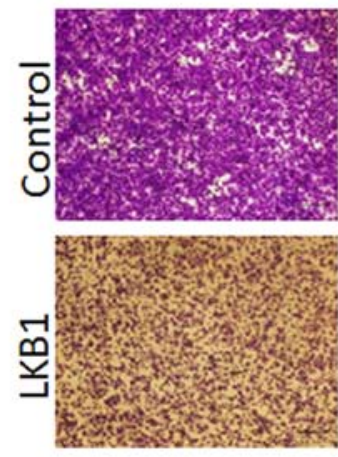

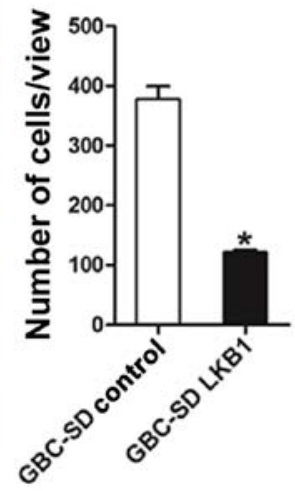

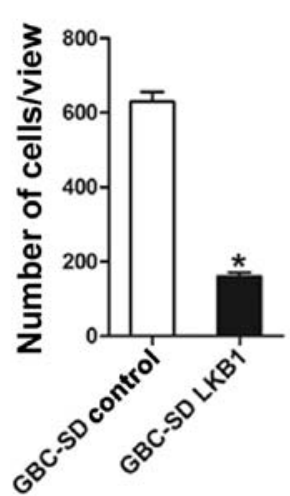

B
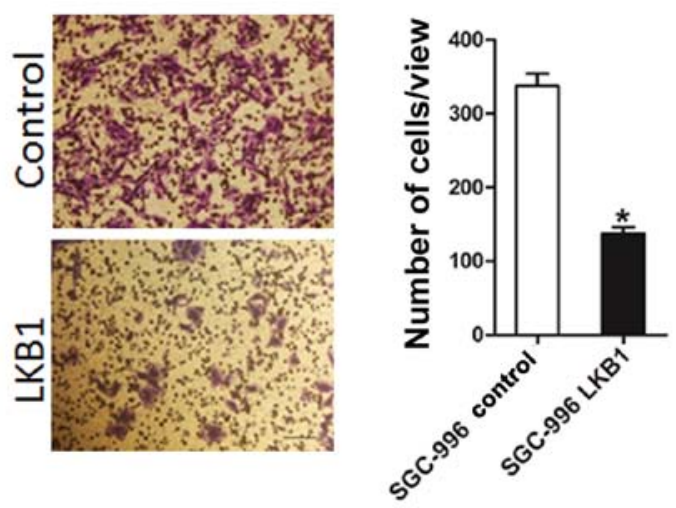

D

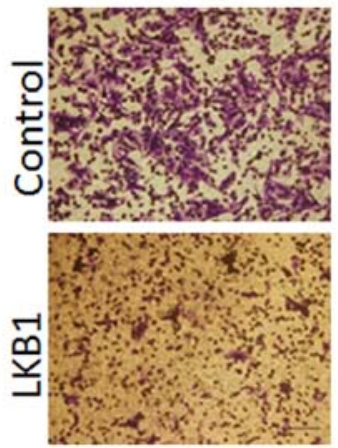

Figure 3. LKB1 overexpression suppresses gallbladder carcinoma (GBC) cell migration and invasion. (A and B) Migration assay was performed utilizing Transwell assay. (C) The invasive properties of the GBC-SD cells overexpressing LKB1 and the control cells were analyzed using a Matrigel-coated Boyden chamber. (D) The invasive ability of the SGC-996 cells overexpressing LKB1 and the control cells were examined using an invasion chamber.

compared with the paired non-tumorous tissues, with higher LKB1 transcripts observed in $17.5 \%$ of the patients. Moreover, the results of western blot analysis revealed the downregulation of LKB1 expression in the tumor tissues and the upregulation in the surrounding normal tissues (Fig. 1B). Furthermore, immumohistochemical staining revealed that the expression of LKB1 was decreased in the patients with GBC (Fig. 1C).

According to the LKB1 mRNA expression levels which were above or below the median score, 105 patients with GBC were classified into the 'high-LKB1' expression group $(n=52)$ and the 'low-LKB1' expression group $(n=53)$. The survival time in the 'low-LKB1' expression group was shorter than that in the 'high-LKB1' expression group (Fig. 1D and E). Taken together, LKB1 could be a valuable prognostic factor for GBC patients.

Overexpression of LKBI suppresses GBC cell proliferation. In order to elucidate the role of LKB1 in GBC cell growth, GBC-SD and SGC-996 cells were infected with LKB1 overexpression lentivirus. The stable infectants were examined by RT-qPCR and western blot analysis (Fig. 2A). As was expected, LKB1 overexpression suppressed the markedly proliferation of the GBC cells (Fig. 2B). Moreover, GBC cells stably overexpressing LKB1 formed smaller and fewer colonies (Fig. 2C). Consistently, 5-ethynyl-2'-deoxyuridine (EdU) staining confirmed that the ectopic expression of LKB1 suppressed cell proliferation (Fig. 2D). Taken together, the above-mentioned results demonstrated that LKB1 suppressed GBC cell growth.

Overexpression of LKB1 suppresses $G B C$ cells migration and invasion in vitro. To further elucidate the effects of LKB1 on GBC cell metastasis, Transwell assay was performed, which demonstrated that the migratory ability of the GBC cells was attenuated following the ectopic overexpression of LKB1 (Fig. 3A and B). In addition, the invasive ability of the GBC cells was impaired following the overexpression of LKB1 (Fig. 3C and D). Collectively, our results demonstrated that LKB1 disrupted the metastatic potential of GBC cells.

Downregulation of LKB1 in GBC CSCs. It has been reported that LKB1 is downregulated in breast stem-like cells (26). However, whether LKB1 regulates the maintenance of GBC CSCs remained unknown. In this study, we found that cluster of differentiation (CD)44-positive $\left(\mathrm{CD} 44^{+}\right)$or CD133-positive $\left(\mathrm{CD}_{133}{ }^{+}\right) \mathrm{GBC}$ cells, which are considered as GBC CSCs, exhibited a decreased expression of LKB1 compared with the CD44- or CD133- cells (Fig. 4A and B). In serial passages of GBC-SD or SGC-996 spheroids, the expression of LKB1 was also found to be gradually decreased (Fig. 4C). Of note, LKB1 expression was partially recovered when the spheroids were re-seeded in the attached plates (Fig. 4D). 
A
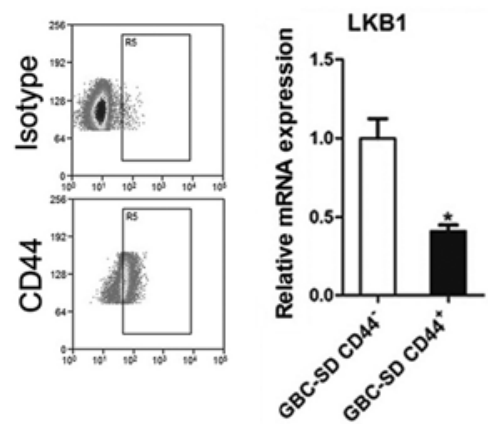

C

LKB1

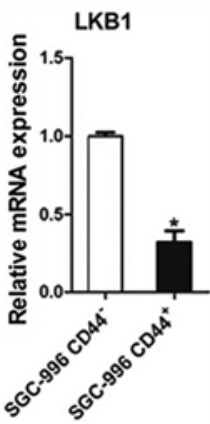

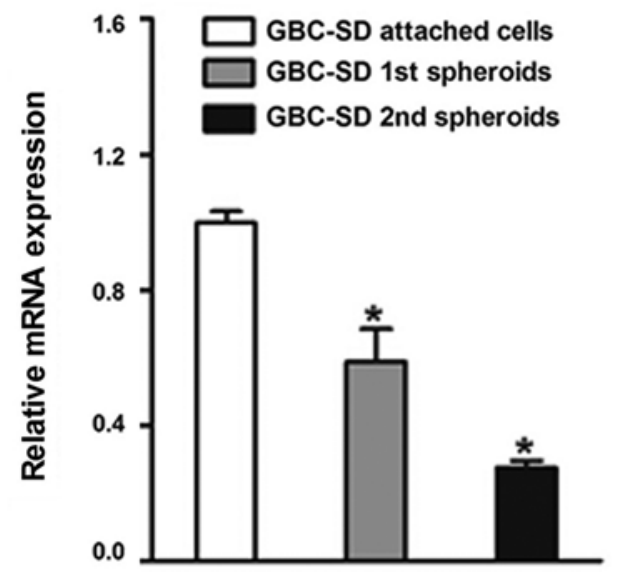

LKB1

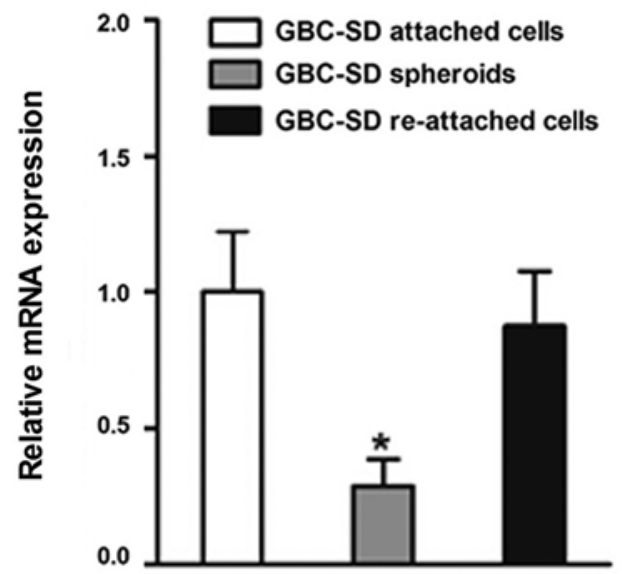

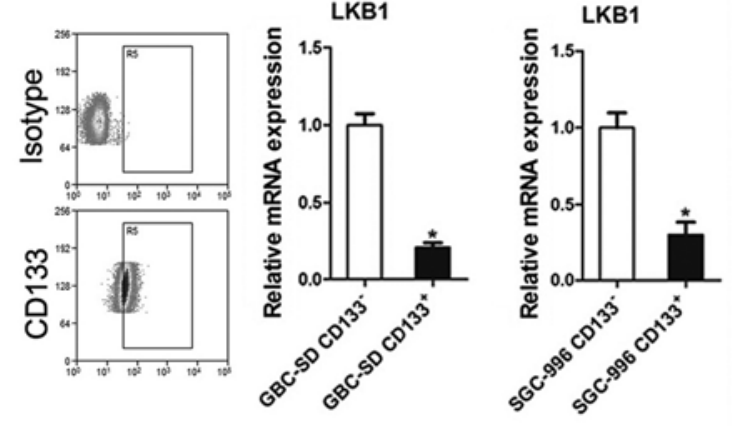
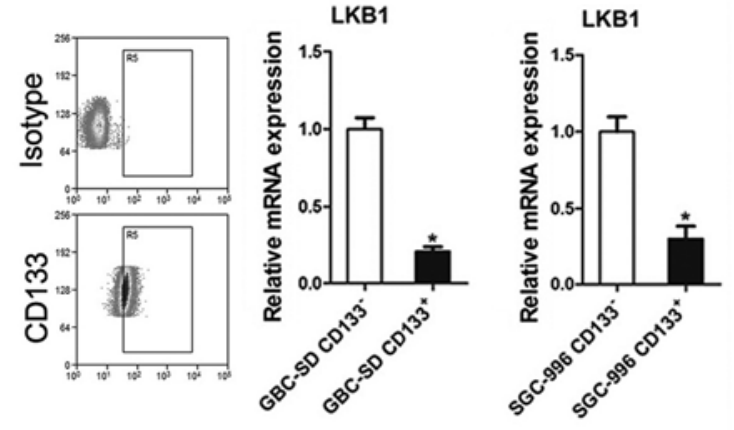

B

LKB1

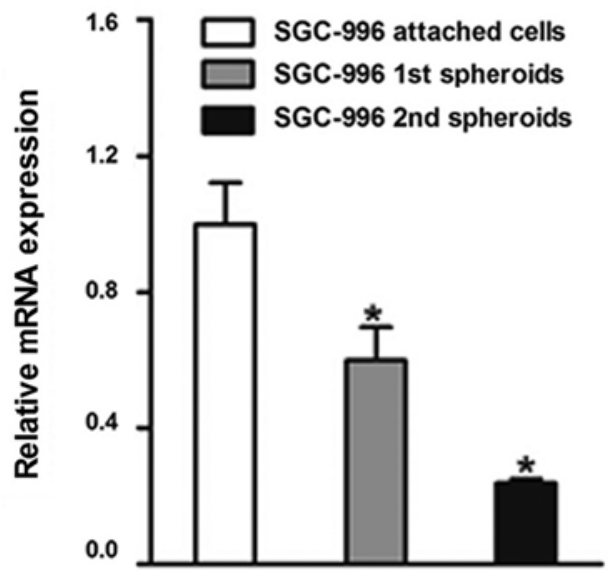

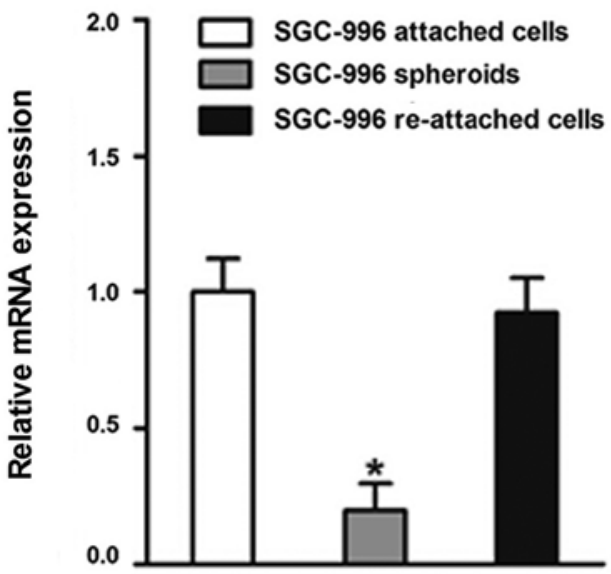

Figure 4. LKB1 is downregulated in gallbladder carcinoma (GBC) cancer stem cells (CSCs). (A) CD44+ $\mathrm{GBC}$ cells were sorted by flow cytometry and the expression of LKB1 was determined by RT-qPCR assay. (B) CD133+ GBC cells were sorted by flow cytometry and the expression of LKB1 was determined by RT-qPCR assay. (C) The expression of LKB1 in serial passages of GBC-SD or SGC-996 spheroids was examined by RT-qPCR. (D) GBC cell-derived spheroids were trypsinized and cultured in attachment conditions. LKB1 expression in spheroids versus re-attached cells was compared by RT-qPCR.

$L K B 1$ represses $G B C$ CSCs expansion. To explore the significance of LKB1 in GBC CSCs, LKB1 stable overexpressing transfectants of GBC cells were used. As expected, fewer spheroids were formed in the GBC cells overexpressing LKB1 as compared with the control cells (Fig. 5A). Consistently, an in vitro limiting dilution assay 
A
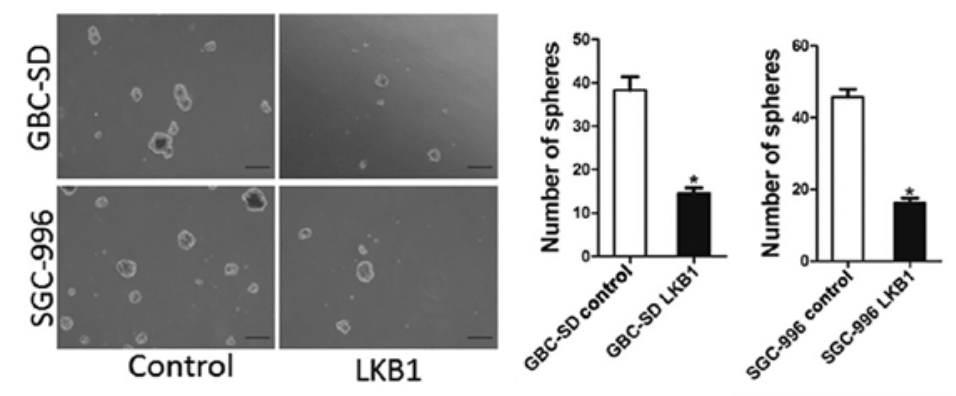

B
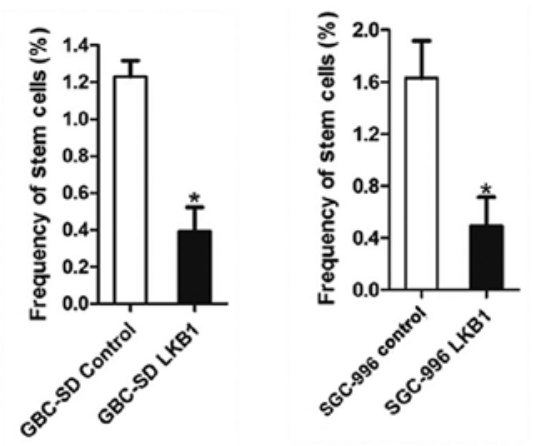

C
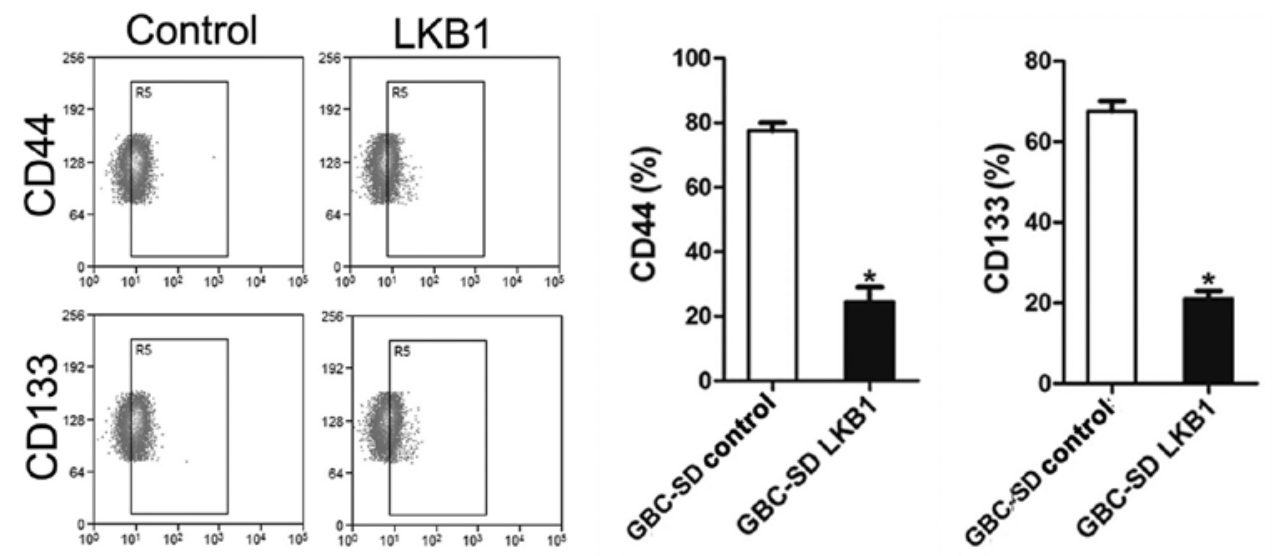

D
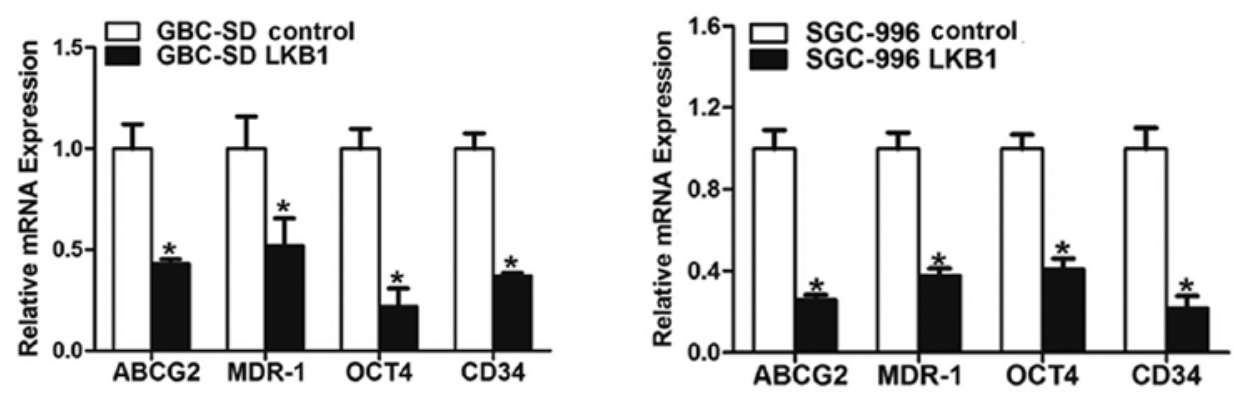

Figure 5. Overexpression of LKB1 suppresses gallbladder carcinoma (GBC) cancer stem cell (CSC) propagation. (A) Representative images of spheres formed from GBC-SD or SGC-996 cells. The number of the formed spheres was counted and compared. (B) The frequency of gallbladder CSCs in SGC-996 or GBC-SD cells overexpressing LKB1 and the control cells was determined by in vitro limiting dilution assay. (C) The proportion of CD44 $4^{+}$or CD24 $4^{+}$in the GBC-SD cells overexpressing LKB1 and the control cells that formed spheres was examined by flow cytometry. (D) The stemness-associated transcription factors and CSCs markers in GBC-SD/SGC-996 cells overexpressing LKB1 or the control cells was examined by RT-qPCR.

illustrated that LKB1 overexpression was markedly decreased in the CSC population in the GBC cells (Fig. 5B). Moreover, the expression levels of LKB1 (Fig. 5C and D), GBC stemnessassociated transcription factors and CSC markers were also suppressed in the spheroids overexpressing which further supported that LKB1 could suppress GBC CSCs expansion.

$L K B 1$ inhibits $G B C$ cell progression via the JAK/STAT3 cascade. Several signaling pathways, including JAK/STAT3,
PI3K/Akt, MEK/ERK and EMT have been reported to play a role in the proliferation of GBC cells (27-32). In this study, our data demonstrated that PI3K/Akt and MEK/ERK pathways, and EMT were not affected by LKB1 overexpression, while the phosphorylation of the STAT3 molecule was evidently activated in both the SGC-996 and GBC-SD LKB1 control cells (Fig. 6A). STAT3 reporter assay further confirmed the effects of LKB1 on STAT3 activation (Fig. 6B). In addition, the use of the JAK2/STAT3 inhibitor, AZD-1480, led to the 


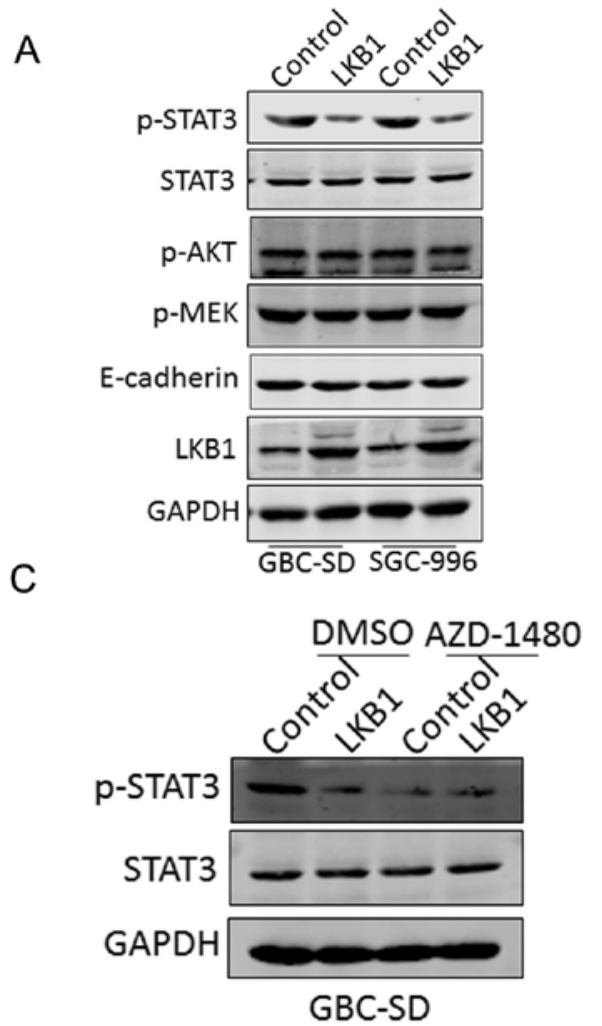

D
B
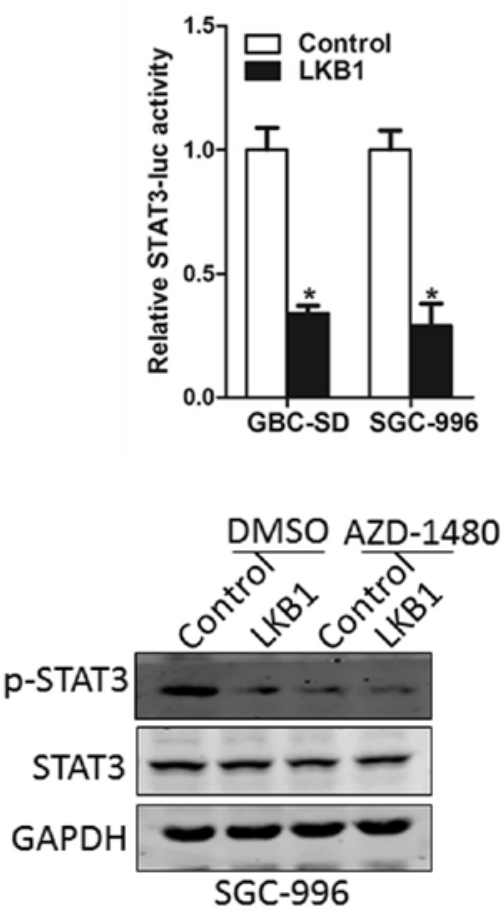

$\mathrm{F}$
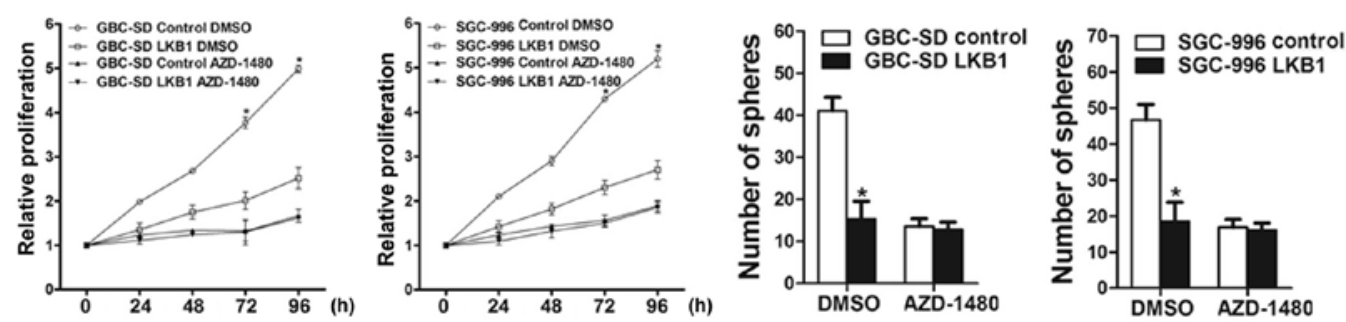

E
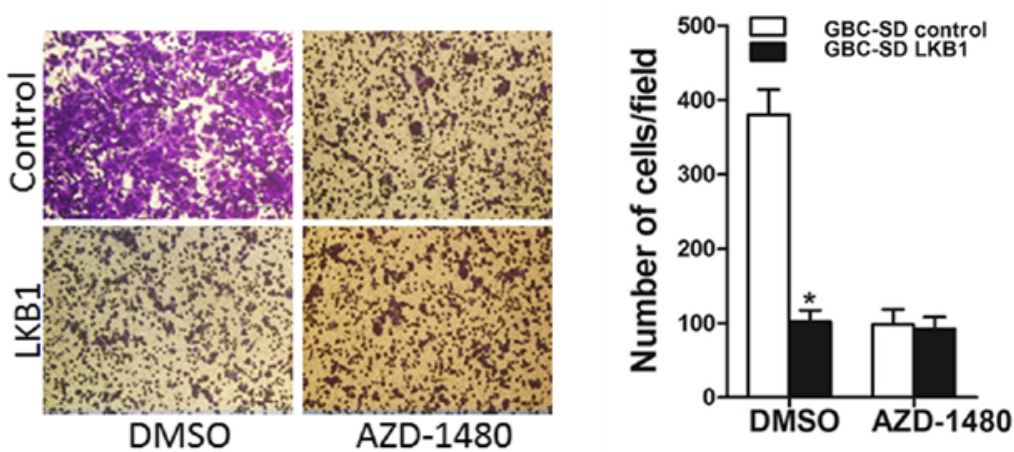

Figure 6. LKB1 suppresses JAK/STAT3 activation in gallbladder carcinoma (GBC) cells. (A) The phosphorylation status of STAT3, AKT, MEK and E-cadherin in SGC-996 or GBC-SD LKB1 cells and the control cells was examined by western blot analysis. (B) Luciferase activity in STAT3-luc transfected GBC-SD/ SGC-996 cell lysates was detected and normalized by Renilla luciferase activity. (C) GBC-SD or SGC-996 cells overexpressing LKB1 and the control cells were treated with AZD-1480 (10 $\mu \mathrm{M})$ for $36 \mathrm{~h}$, then subjected to western blot analysis. (D) The proliferation of SGC-996 or GBC-SD cells overexpressing LKB1 and the control cells in the presence of AZD-1480 (10 $\mu \mathrm{M})$ or DMSO, respectively, was measured by CCK8 assay. (E) Migration assay was examined using the GBC-SD cells overexpressing LKB1 and the control cells treated with AZD-1480 (10 $\mu \mathrm{M})$ or DMSO, respectively. (F) Spheroid formation assay was performed using the GBC-SD or SGC-996 cells overexpressing LKB1 and the control cells treated with or without AZD-1480 (10 $\mu$ M).

distinct inactivation of the phosphorylation of STAT3 in the LKB1-overexpressig GBC cells and the control cells (Fig. 6C). More importantly, the inhibitor, AZD-1480, diminished the distinct differences in the growth capacity between the LKB1-overexpressing GBC cells and the control cells (Fig. 6D), and also eliminated the differences in the metastatic 
ability between the LKB1-overexpressing GBC cells and the control cells (Fig. 6E). The use of AZD-1480 also abolished the distinct differences in the self-renewal ability between the LKB1-overexpressing GBC cells and the control cells (Fig. 6F), suggesting that LKB1 suppressed the GBC cell growth ability by inhibiting JAK2/STAT3 signaling.

\section{Discussion}

GBC is the most common malignant tumors of the biliary system. The majority of patients with GBC are diagnosed at a late stage or are affected by distant metastasis, and thus, the prognosis is poor (33). Post-operative recurrence in patients with GBC remains very high, and treatments involving radiotherapy or chemotherapy are only effective for a few patients (34). However, the underlying molecular mechanisms responsible for the development of GBC remain elusive. It is therefore necessary to obtain a better understanding of the molecular mechanisms behind the pathogenesis of GBC in order to identifying GBC-specific targets for therapeutic intervention. In this study, to the best of our knowledge, we demonstrate for the first time that a decreased expression of LKB1 is associated with the prognosis of patients with GBC, suggesting that LKB1 may thus prove to be a valuable prognostic marker for patients with GBC.

It has been reported that LKB1 functions as a tumor suppressor gene in the initiation and progression of human cancers (35), and may prove to be a novel marker for the diagnosis and treatment of cancers. However, the potential role of LKB1 in GBC has not been reported to date, at least to the best of our knowledge. In this study, LKB1 was found to be downregulated in GBC tissues and to be associated with the prognosis of patients with GBC. We also found that the ectopic overexpression of the LKB1 gene by lentivirus transfection inhibited GBC cell proliferation and metastasis in vitro.

The presence of CSCs in solid tumors has been confirmed, and these cells have the ability of self-renewal and differentiation, a high tumorigenic potential, and resistance to chemotherapeutics (36). The existence of GBC CSCs is considered to be the origin of the chemoresistance and recurrence of patients with GBC (22). Thus, it is mandatory that the molecular mechanisms underlying GBC CSC regulation are investigated, so as to develop novel therapeutic strategies targeting CSCs. It has been reported that LKB1 regulates the quiescence and metabolic homeostasis of hematopoietic stem cells (13). However, whether LKB1 is involved in GBC CSC expansion remains to be fully elucidated. The data from the present study indicated that LKB1 was downregulated in the CD44- and CD133-positive GBC cells (CD44 and CD133 are markers of CSCs). Moreover, LKB1 overexpression in the GBC cells suppressed the self-renewal capacity of the GBC CSCs, and downregulated the levels of stemness-associated transcription factors and CSC markers.

Accumulating evidence has illustrated that the JAK/STAT3 pathway plays a pivotal role in tumor activation, although the detailed underlying mechanisms have yet to be determined (37-39). Activated STAT3 modulates the function of numerous substrates, including cell proliferation and apoptosis (40). There is ample evidence to indicate that the STAT3 pathway is uncontrolled in $\operatorname{GBC}(28,41)$. It was found in our study that LKB1 plays a negative role in GBC cells and inhibits GBC cell growth and metastasis by inactivating STAT3 signaling. In addition, these effects were attenuated by the JAK2 inhibitor, AZD-1480. Mouse embryos with STAT3-deficiency have also been shown to be unable to develop beyond embryonic day 7, when gastrulation begins (42). STAT3 activation has been shown to be involved in the early developmental stage of embryonic stem cells (43). It has been reported that IL-6 promotes CSC expansion via STAT3 activation in numerous tumors, including breast, colon, lung, prostate cancers as well as GBC $(27,44-46)$. The data of the present study demonstrated that LKB1 suppressed GBC CSC expansion via the inactivation of JAK/STAT3 pathway. Furthermore, these effects were abolished by JAK2 inhibitor, AZD-1480.

In conclusion, in this study, at least to the best of our knowledge, we demonstrate for the first time that LKB1 is downregulated in GBC tissues, and its ectopic overexpression suppresses the growth, metastasis and self-renewal ability of GBC cells. Moreover, LKB1 suppressed GBC cell progression via dysregulating JAK/STAT3 signaling in vitro. The findings of the present study not only shed new light on the mechanisms responsible for GBC progression, but also suggest that LKB1 may be a novel prognostic marker and a potential therapeutic target against GBC and GBC CSCs.

\section{Acknowledgements}

Not applicable.

\section{Funding}

This study was supported by a grant from the National Natural Science Foundation of China (no. 81472280).

\section{Availability of data and materials}

The analyzed datasets generated during the study are available from the corresponding author on reasonable request.

\section{Authors' contributions}

$\mathrm{XQJ}$ was involved in the conception and design of the study; MTH, JHW, YY, CL, BL and QBCheng were responsible for data acquisition; MTH and JHW were responsible for the analysis and interpretation of the data; MTH was responsible for statistical analysis; JHW was responsible for the drafting of the manuscript; XQJ was responsible for the critical revision of the manuscript; $\mathrm{XQJ}$ was responsible for funding acquisition; MTH, JHW, YY, CL, BL and QBCheng provided administrative and technical support; and XQJ was responsible for study supervision. All authors have read and approved the final manuscript.

\section{Ethics approval and consent to participate}

The procedure of human sample collection was approved by the Ethics Committee of Eastern Hepatobiliary Surgery Hospital. Informed consent was also obtained from all patients prior to obtaining the samples. 


\section{Consent for publication}

Not applicable.

\section{Competing interests}

The authors declare that they have no competing interests.

\section{References}

1. Zhu AX,Hong TS, Hezel AF and Kooby DA: Current management of gallbladder carcinoma. Oncologist 15: 168-181, 2010.

2. Wistuba II and Gazdar AF: Gallbladder cancer: Lessons from a rare tumour. Nat Rev Cancer 4: 695-706, 2004.

3. Lazcano-Ponce EC, Miquel JF, Muñoz N, Herrero R, Ferrecio C, Wistuba II, Alonso de Ruiz P, Aristi Urista G and Nervi F Epidemiology and molecular pathology of gallbladder cancer. CA Cancer J Clin 51: 349-364, 2001.

4. Batra Y, Pal S, Dutta U, Desai P, Garg PK, Makharia G, Ahuja V, Pande GK, Sahni P, Chattopadhyay TK, et al: Gallbladder cancer in India: A dismal picture. J Gastroenterol Hepatol 20: 309-314, 2005 .

5. Wu XS, Shi LB, Li ML, Ding Q, Weng H, Wu WG, Cao Y, Bao RF, Shu YJ, Ding QC, et al: Evaluation of two inflammationbased prognostic scores in patients with resectable gallbladder carcinoma. Ann Surg Oncol 21: 449-457, 2014.

6. Butte JM, Matsuo K, Gönen M, D'Angelica MI, Waugh E Allen PJ, Fong Y, DeMatteo RP, Blumgart L, Endo I, et al: Gallbladder cancer: Differences in presentation, surgical treatment, and survival in patients treated at centers in three countries. J Am Coll Surg 212: 50-61, 2011

7. Li M, Zhang Z, Li X, Ye J, Wu X, Tan Z, Liu C, Shen B, Wang XA $\mathrm{Wu} \mathrm{W}$, et al: Whole-exome and targeted gene sequencing of gallbladder carcinoma identifies recurrent mutations in the ErbB pathway. Nat Genet 46: 872-876, 2014.

8. McInnes KJ, Brown KA, Hunger NI and Simpson ER: Regulation of LKB1 expression by sex hormones in adipocytes. Int $\mathrm{J}$ Obes 36: 982-985, 2012.

9. Mans LA, Querol Cano L, van Pelt J, Giardoglou P, Keune WJ and Haramis AG: The tumor suppressor LKB1 regulates starvation-induced autophagy under systemic metabolic stress. Sci Rep 7: 7327, 2017.

10. Yamada E and Bastie CC: Disruption of Fyn SH3 domain interaction with a proline-rich motif in liver kinase $\mathrm{B} 1$ results in activation of AMP-activated protein kinase. PLoS One 9: e89604, 2014.

11. Zheng X, Chi J, Zhi J, Zhang H, Yue D, Zhao J, Li D, Li Y, Gao M and Guo J: Aurora-A-mediated phosphorylation of LKB1 compromises LKB1/AMPK signaling axis to facilitate NSCLC growth and migration. Oncogene 37: 502-511, 2018.

12. Jenne DE, Reimann H, Nezu J, Friedel W, Loff S, Jeschke R, Müller O, Back W and Zimmer M: Peutz-Jeghers syndrome is caused by mutations in a novel serine threonine kinase. Nat Genet 18: 38-43, 1998.

13. Zhang H, Fillmore Brainson C, Koyama S, Redig AJ, Chen T, Li S, Gupta M, Garcia-de-Alba C, Paschini M, Herter-Sprie GS, et al Lkb1 inactivation drives lung cancer lineage switching governed by Polycomb Repressive Complex 2. Nat Commun 8: 14922, 2017.

14. Singh AK, Arya RK, Maheshwari S, Singh A, Meena S, Pandey P, Dormond O and Datta D: Tumor heterogeneity and cancer stem cell paradigm: Updates in concept, controversies and clinical relevance. Int J Cancer 136: 1991-2000, 2015.

15. Kreso A and Dick JE: Evolution of the cancer stem cell model Cell Stem Cell 14: 275-291, 2014.

16. Sharma KL, Yadav A, Gupta A, Tulsayan S, Kumar V, Misra S, Kumar A and Mittal B: Association of genetic variants of cancer stem cell gene CD44 haplotypes with gallbladder cancer susceptibility in North Indian population. Tumour Biol 35: 2583-2589, 2014

17. Yin S, Li J, Hu C, Chen X, Yao M, Yan M, Jiang G, Ge C, Xie H, Wan D, et al: CD133 positive hepatocellular carcinoma cells possess high capacity for tumorigenicity. Int J Cancer 120 1444-1450, 2007.

18. Yamashita T, Ji J, Budhu A, Forgues M, Yang W, Wang HY, Jia H, Ye Q, Qin LX, Wauthier E, et al: EpCAM-positive hepatocellular carcinoma cells are tumor-initiating cells with stem/progenitor cell features. Gastroenterology 136: 1012-1024, 2009.
19. Jin K, Xiang Y, Tang J, Wu G, Li J, Xiao H, Li C, Chen Y and Zhao J: miR-34 is associated with poor prognosis of patients with gallbladder cancer through regulating telomere length in tumor stem cells. Tumour Biol 35: 1503-1510, 2014.

20. Yadav A, Gupta A, Rastogi N, Agrawal S, Kumar A, Kumar V and Mittal B: Association of cancer stem cell markers genetic variants with gallbladder cancer susceptibility, prognosis, and survival. Tumour Biol 37: 1835-1844, 2016.

21. Wang X: Identification of cancer stem cells in gallbladder carcinoma: A platform for the discovery of novel therapeutic targets. Cancer Biol Ther 10: 1191-1193, 2010.

22. Shi C, Tian R, Wang M, Wang X, Jiang J, Zhang Z, Li X, He Z, Gong W and Qin R: CD $44^{+} \mathrm{CD} 133^{+}$population exhibits cancer stem cell-like characteristics in human gallbladder carcinoma. Cancer Biol Ther 10: 1182-1190, 2010.

23. Shi CJ, Gao J, Wang M, Wang X, Tian R, Zhu F, Shen M and Qin RY: CD133(+) gallbladder carcinoma cells exhibit selfrenewal ability and tumorigenicity. World J Gastroenterol 17: 2965-2971, 2011

24. Han T, Xiang DM, Sun W, Liu N, Sun HL, Wen W, Shen WF, Wang RY, Chen C, Wang X, et al: PTPN11/Shp2 overexpression enhances liver cancer progression and predicts poor prognosis of patients. J Hepatol 63: 651-660, 2015.

25. Roccograndi L, Binder ZA, Zhang L, Aceto N, Zhang Z, Bentires-Alj M, Nakano I, Dahmane N and O'Rourke DM: SHP2 regulates proliferation and tumorigenicity of glioma stem cells. J Neurooncol 135: 487-496, 2017.

26. Sengupta S, Nagalingam A, Muniraj N, Bonner MY, Mistriotis P, Afthinos A, Kuppusamy P, Lanoue D, Cho S, Korangath P, et al: Activation of tumor suppressor LKB1 by honokiol abrogates cancer stem-like phenotype in breast cancer via inhibition of oncogenic Stat3. Oncogene 36: 5709-5721, 2017.

27. Enyu L, Na W, Chuanzong Z, Ben W, Xiaojuan W, Yan W, Zequn L, Jianguo H, Jiayong W, Benjia L, et al: The clinical significance and underlying correlation of pStat-3 and integrin $\alpha \mathrm{v} \beta 6$ expression in gallbladder cancer. Oncotarget 8 : 19467-19477, 2017

28. Kong X, Ma MZ, Zhang Y, Weng MZ, Gong W, Guo LQ, Zhang JX, Wang GD, Su Q, Quan ZW, et al: Differentiation therapy: Sesamin as an effective agent in targeting cancer stem-like side population cells of human gallbladder carcinoma. BMC Complement Altern Med 14: 254, 2014

29. Jin YP, Hu YP, Wu XS, Wu YS, Ye YY, Li HF, Liu YC, Jiang L, Liu FT, Zhang YJ, et al: miR-143-3p targeting of ITGA6 suppresses tumour growth and angiogenesis by downregulating PLGF expression via the PI3K/AKT pathway in gallbladder carcinoma. Cell Death Dis 9: 182, 2018.

30. Mohri D, Ijichi H, Miyabayashi K, Takahashi R, Kudo Y, Sasaki T, Asaoka Y, Tanaka Y, Ikenoue T, Tateishi K, et al: A potent therapeutics for gallbladder cancer by combinatorial inhibition of the MAPK and mTOR signaling networks. J Gastroenterol 51: 711-721, 2016.

31. Wang SH, Wu XC, Zhang MD, Weng MZ, Zhou D and Quan ZW: Upregulation of H19 indicates a poor prognosis in gallbladder carcinoma and promotes epithelial-mesenchymal transition. Am J Cancer Res 6: 15-26, 2015.

32. Xiong L, Wen Y, Miao X and Yang Z: NT5E and FcGBP as key regulators of TGF-1-induced epithelial-mesenchymal transition (EMT) are associated with tumor progression and survival of patients with gallbladder cancer. Cell Tissue Res 355: 365-374, 2014.

33. Zhao S, Cao Y, Liu SB, Wang XA, Bao RF, Shu YJ, Hu YP, Zhang YJ, Jiang L, Zhang F, et al: The E545K mutation of PIK3CA promotes gallbladder carcinoma progression through enhanced binding to EGFR. J Exp Clin Cancer Res 35: 97, 2016.

34. Caldow Pilgrim CH, Groeschl RT, Quebbeman EJ and Gamblin TC: Recent advances in systemic therapies and radiotherapy for gallbladder cancer. Surg Oncol 22: 61-67, 2013.

35. Trapp EK, Majunke L, Zill B, Sommer H, Andergassen U, Koch J, Harbeck N, Mahner S, Friedl TWP, Janni W, et al: LKB1 pro-oncogenic activity triggers cell survival in circulating tumor cells. Mol Oncol 11: 1508-1526, 2017.

36. Zhang S, Balch C, Chan MW, Lai HC, Matei D, Schilder JM, Yan PS, Huang TH and Nephew KP: Identification and characterization of ovarian cancer-initiating cells from primary human tumors. Cancer Res 68: 4311-4320, 2008.

37. Wang X, Sun W, Shen W, Xia M, Chen C, Xiang D, Ning B, Cui X, Li H, Li X, et al: Long non-coding RNA DILC regulates liver cancer stem cells via IL-6/STAT3 axis. J Hepatol 64: 1283-1294, 2016 
38. Hill DG, Yu L, Gao H, Balic JJ, West A, Oshima H, McLeod L, Oshima M, Gallimore A, D'Costa K, et al: Hyperactive gp130/ STAT3-driven gastric tumourigenesis promotes submucosal tertiary lymphoid structure development. Int J Cancer: Feb 8, 2018 (Epub ahead of print). doi: 10.1002/ijc.31298..

39. Johnson DE, O'Keefe RA and Grandis JR: Targeting the IL-6/ JAK/STAT3 signalling axis in cancer. Nat Rev Clin Oncol 15: 234-248, 2018

40. Jin G, Yang Y, Liu K, Zhao J, Chen X, Liu H, Bai R, Li X, Jiang Y, Zhang X, et al: Combination curcumin and (-)-epigallocatechin-3-gallate inhibits colorectal carcinoma microenvironment-induced angiogenesis by JAK/STAT3/IL-8 pathway. Oncogenesis 6: e384, 2017.

41. Wang W, Zhan M, Li Q, Chen W, Chu H, Huang Q, Hou Z, Man M and Wang J: FXR agonists enhance the sensitivity of biliary tract cancer cells to cisplatin via SHP dependent inhibition of Bcl-xL expression. Oncotarget 7: 34617-34629, 2016.

42. Takeda K, Noguchi K, Shi W, Tanaka T, Matsumoto M, Yoshida N, Kishimoto T and Akira S: Targeted disruption of the mouse Stat3 gene leads to early embryonic lethality. Proc Natl Acad Sci USA 94: 3801-3804, 1997.
43. He N, Chen X, Wang D, Xu K, Wu L, Liu Y, Tao H, Zhao Q, Cao X, Li Y, et al: VE-cadherin regulates the self-renewal of mouse embryonic stem cells via LIF/Stat3 signaling pathway. Biomaterials 158: 34-43, 2018

44. Schroeder A, Herrmann A, Cherryholmes G, Kowolik C, Buettner R, Pal S, Yu H, Müller-Newen G and Jove R: Loss of androgen receptor expression promotes a stem-like cell phenotype in prostate cancer through STAT3 signaling. Cancer Res 74: 1227-1237, 2014.

45. Korkaya H, Kim GI, Davis A, Malik F, Henry NL, Ithimakin S, Quraishi AA, Tawakkol N, D'Angelo R, Paulson AK, et al: Activation of an IL6 inflammatory loop mediates trastuzumab resistance in HER $2^{+}$breast cancer by expanding the cancer stem cell population. Mol Cell 47: 570-584, 2012.

46. Jinushi M, Chiba S, Yoshiyama H, Masutomi K, Kinoshita I, Dosaka-Akita H, Yagita H, Takaoka A and Tahara H: Tumorassociated macrophages regulate tumorigenicity and anticancer drug responses of cancer stem/initiating cells. Proc Natl Acad Sci USA 108: 12425-12430, 2011. 